\section{Response of Olive Cultivars to Stem Puncture Inoculation with a Defoliating Pathotype of Verticillium dahliae}

\author{
Francisco Javier López-Escudero ${ }^{\mathbf{1}}$ and Miguel Ángel Blanco-López \\ Departamento de Agronomiá, Universidad de Córdoba, Campus Universitario \\ de Rabanales, Edificio Celestino Mutis (C4), 14071, Córdoba, Spain
}

\section{Carmen Del Río Rincón and Juan Manuel Caballero Reig IFAPA, CIFA Alameda del Obispo, Apdo. 3092, 14080, Córdoba, Spain}

Additional index words. breeding selection programs, Olea europaea, Olive World Germplasm Bank, rootstock, verticillium wilt

\begin{abstract}
The resistance of 26 olive (Olea europaea L.) cultivars to the defoliating pathotype of Verticillium dahliae Kleb. was evaluated in experiments under controlled conditions by stem puncture inoculation. The area under disease progress curve with reference to the maximum value potentially reached over the assessment period (AUDPCP), calculated from the symptom severity values (0-4 rating scale), was the main parameter for assessing resistance, and the percentage of dead plants (PDP), the final mean symptom severity (FMS), and the disease recovery were used as additional parameters. Five cultivars were catalogued as extremely susceptible showing values of AUDPCP, PDP, and FMS higher than $70 \%, 50 \%$, and 3.0 , respectively. Six other cultivars exhibited AUDPCP values ranging from $50 \%$ to $70 \%$ and FMS higher than 3.0 and were classified as susceptible. A group of 11 cultivars, including 'Koroneiki', was moderately susceptible with AUDPCP ranging from $31 \%$ to $50 \%$. Finally, 'Frantoio', 'Grosal de Albocafer', 'Kato Drys', and 'Manzanilla Picúa' showed maximum AUDPCP values of $22 \%$, no dead plants, and slight symptom severity, being classified as resistant. Stem puncture inoculation was an effective tool for identifying resistance in olive cultivars, but a reduction or a delay in the disease symptom expression of plants was observed regarding the symptom progress observed in plants root dip-inoculated in previous works of resistance assessment. These differences were more pronounced in susceptible than in resistant cultivars.
\end{abstract}

Verticillium wilt of olive (VWO), incited by Verticillium dahliae Kleb., has become the most destructive disease of olive throughout the Mediterranean basin (Al-Ahamad and Mosli, 1993; Blanco-López et al., 1984; Hiemstra and Harris, 1998; Serrhini and Zeroual, 1995). Particularly, the disease has been described as a major problem in soils infested with highly virulent defoliating isolates of the pathogen in Andalucía (southern Spain) (López-Escudero and Blanco-López, 2001), where more than 2.4 million ha of olive are grown (Civantos, 2004). Like other vascular wilt diseases, the use of resistance is the most effective tool for controlling VWO. In this respect, olive provides a wide genetic resource because more than 800 olive cultivars are introduced in collections around the world (Caballero and Del Río, 2005). Unfor-

Received for publication 9 Sept. 2006. Accepted for publication 16 Nov. 2006.

This research was funded by projects RTA-04129-C7-3 of INIA and CAO00-011-C12-03 from the Consejería de Agricultura y Pesca, Junta de Andalucía, Spain.

${ }^{1}$ To whom reprint requests should be addressed; e-mail ag2loesj@uco.es. tunately, major cultivars from Spain, Italy, and other important olive oil-producing countries are susceptible to this pathogen (Cirulli and Montemurro, 1976; López-Escudero et al., 2004; Martos-Moreno et al., 2006; Paplomatas and Elena, 2001; Pennisi et al., 1993; Raya-Ortega, 2005). Efforts have been focused on the assessment of olive resistance to Verticillium wilt, aimed at selecting resistant cultivars for breeding or rootstock selection programs or for replanting trees killed by wilt in established olive orchards. This research has been ongoing since 1994 in the Departamento de Agronomía of Córdoba University (Spain) using olive plant material from the Olive World Germplasm Bank (OWGB) of IFAPA, Centro de Investigación y Formación Agraria "Alameda del Obispo" (Junta de Andalucía, Córdoba, Spain) (Caballero et al., 2006). In this program, root dip inoculation has been the most common technique for evaluating resistance in olive, because it reliably reproduces the infection process incited by $V$. dahliae (Blanco-López et al., 1998; López-Escudero et al., 2004). Nevertheless, other works have revealed that stem puncture inoculation can also be a useful technique for assessing olive resistance to $V$. dahliae (Markakis et al., 2006;
Paplomatas and Elena, 2001; Raya-Ortega, 2005). Other authors have proved that stem puncture is appropriate for large-scale programs of resistance evaluation in avocado (Persea Americana Mill.) (Zentmeyer et al., 1955) or in cocoa (Theobroma cacao L.) (Resende et al., 1995). In olive, this assessment method could provide a preliminary resistance evaluation, which is earlier and quicker to perform, to be then confirmed by the root dipping technique with the cultivars presenting higher resistance level. The objective of this work was to evaluate the resistance to $V$. dahliae in a number of olive cultivars using stem puncture inoculation.

\section{Materials and Methods}

Plant and fungal material. Twenty-six olive cultivars were inoculated in two experiments under controlled conditions in a growth chamber with the aim to evaluate their resistance to Verticillium dahliae. In Expts. I and II, 9 and 15 olive cultivars were assessed, respectively, both of them repeated twice using four replications (plants) per cultivar and experiment. A similar number of noninoculated plants for each cultivar was included as control in each experiment. The plants were 1-year-old rooted cuttings that were provided by the OWGB. All the plants of each cultivar came from the same mother plant, identified in the bank by its registration number (Table 1).

Plants were inoculated with a cotton defoliating $V$. dahliae isolate, namely V117, from the collection of the Plant Pathology Laboratory of Departamento de Agronomía, Universidad de Córdoba (Blanco-López et al., 1989). Additionally, 'Picual' and 'Frantoio', highly susceptible and moderately resistant cultivars, respectively, to the defoliating isolate of $V$. dahliae (Hartman et al., 1971; López-Escudero et al., 2004; Martos-Moreno et al., 2006; RodríguezJurado et al., 1993) were inoculated in each experiment as reference cultivars.

For preparing the inoculum, the pathogen was transferred from potato dextrose agar (PDA) slants, where it was maintained at $4{ }^{\circ} \mathrm{C}$, to 10 PDA plates, spreading the mycelium uniformly all over the surface of each one. Plates were incubated for $6 \mathrm{~d}$ at $25^{\circ} \mathrm{C}$ in the dark and thereafter the resulting yielded mycelium, together with the upper $1 \mathrm{~mm}$ layer of agar from the plates, were collected by scraping off the surface with a scalpel. Thus, the mixture of mycelium, conidia, and agar was passed three times through a $5-\mathrm{mL}$ syringe to obtain a more fluent inoculum mass. The syringe finally remained loaded the fourth time it was filled, and it was conserved at $4{ }^{\circ} \mathrm{C}$ until inoculation. The inoculum density was $4 \times 10^{8}$ conidia per centimeter cubed.

Plants were inoculated by stem puncture in the upper part of their main stem, at $5 \mathrm{~cm}$ height, by using an accuracy drill (Dremel Multipro 395PT; Dremel Manufacturing Co., Racine, Wis.) with a bit $1-\mathrm{mm}$ thick, that produced a hole that completely pierced the 
Table 1. Values of disease parameters of olive cultivars inoculated with the defoliating isolate V117 of Verticillium dahliae.

\begin{tabular}{lllcccc}
\hline Cultivar name $^{z}$ & $\mathrm{~N}^{\circ}$ Reg $^{\mathrm{y}}$ & Origin & AUDPC $^{\mathrm{x}}$ & FMS $^{\mathrm{w}}$ & PDP $^{\mathrm{v}}$ & Susceptibility $^{\mathrm{u}}$ \\
\hline Macho de Jaén* & $\mathrm{R} 28$ & Spain & 71.7 & 3.6 & 50.0 & ES \\
Chalchali-1 & R789 & Syria & 70.1 & 3.8 & 62.5 & ES \\
Cañivano Negro-1 & R55 & Spain & 65.1 & 3.6 & 62.5 & ES \\
Athalassa & R852 & Cyprus & 64.3 & 3.1 & 37.5 & $\mathrm{~S}$ \\
Mission Moojeski & R708 & USA & 58.2 & 3.6 & 75.0 & ES \\
Aloreña-1 & R829 & Spain & 54.8 & 3.1 & 50.0 & S \\
Figueretes & R822 & Spain & 53.8 & 3.3 & 37.5 & S \\
Mission Nyeland & R716 & USA & 52.9 & 3.4 & 37.5 & S \\
Cordobés Arroyo de la Luz & R514 & Spain & 50.2 & 3.5 & 75.0 & ES \\
Picual*t & R9 & Spain & 49.2 & 3.0 & 44.0 & S \\
Carrasqueño de Porcuna & R795 & Spain & 43.7 & 2.6 & 25.0 & MS \\
Flasou & R851 & Cyprus & 41.5 & 3.1 & 25.0 & S \\
Negrillo de Andujar & R793 & Spain & 38.6 & 2.4 & 37.5 & MS \\
Verdial de Vélez-Málaga-1 & R51 & Spain & 38.1 & 2.3 & 12.5 & MS \\
Maelia & R856 & Israel & 38.1 & 2.1 & 0.0 & MS \\
Kiti & R850 & Cyprus & 36.7 & 2.0 & 12.5 & MS \\
Pajarera & R771 & Spain & 34.3 & 1.6 & 0.0 & MS \\
Jlot & R976 & Syria & 32.3 & 1.8 & 0.0 & MS \\
Koroneiki* & R218 & Greece & 29.8 & 1.5 & 12.5 & MS \\
Kato Drys & R848 & Cyprus & 22.0 & 1.1 & 0.0 & R \\
Corneja & R511 & Spain & 21.8 & 1.2 & 12.5 & MS \\
De Sal & R420 & Spain & 21.4 & 1.3 & 12.5 & MS \\
Manzanilla Picúa & R377 & Spain & 17.0 & 1.1 & 0.0 & R \\
Bodoquera* & R631 & Spain & 16.2 & 1.7 & 0.0 & MS \\
Grosal de Albocafer & R811 & Spain & 13.4 & 0.9 & 0.0 & R \\
Frantoio*t & R80 & Italy & 10.2 & 0.5 & 0.0 & R \\
\hline Vareta & &
\end{tabular}

${ }^{\mathrm{z}}$ Varietal denomination planted in the Olive World Germplasm Bank of Córdoba, Spain.

${ }^{\mathrm{y}}$ Registration number in this bank.

${ }^{x} \mathrm{AUDPCP}=$ area under the disease progress curve with reference to the maximum value potentially reached over the assessment period.

${ }^{\mathrm{w}} \mathrm{FMS}$ = final mean severity of symptoms 12 weeks after inoculation.

${ }^{\mathrm{v} P D P}=$ percentage of dead plants.

"The values for the reference cultivars Picual and Frantoio are the means of Expts. I and II.

'HR = highly resistant; $\mathrm{R}=$ resistant; $\mathrm{MS}=$ moderately susceptible; $\mathrm{S}=$ susceptible; $\mathrm{ES}=$ extremely susceptible. Susceptibility was determined from the AUDPCP, FMS, and PDP 12 weeks after inoculation and other complementary criteria such as the shape of the disease progress curve and recovery from the disease. Resistance categories correspond to the following ranges of AUDPC for the defoliating isolate of V. dahliae: $\mathrm{HR}=0 \%$ to $10 \% ; \mathrm{R}=11 \%$ to $30 \%$; $\mathrm{MS}=31 \%$ to $50 \% ; \mathrm{S}=51 \%$ to $70 \%$; $\mathrm{ES}=71 \%$ to $100 \%$. *Authenticated accession; -1 = erroneous name. One-year-old potted olive plants were inoculated by stem puncture with a cotton-defoliating isolate of Verticillium dahliae. Symptom severity was assessed weekly from 2 to 12 weeks after inoculation.

stem. Afterward, plants were placed horizontally and an inoculum mass was injected with the syringe inside the hole. A rectangular laboratory film sheet was used for impeding the outflow of the mass through the other side of the hole sealing it up by wrapping the stem. Control plants were inoculated with the same procedure but inoculum consisted of an agar mass coming from nonsowed PDA plates. Plants were incubated in a growth chamber maintained at $22 \pm 2{ }^{\circ} \mathrm{C}$ with the light and humidity levels adjusted to a photoperiod of $14 \mathrm{~h}\left(216 \mu \mathrm{mol} \cdot \mathrm{m}^{-2} \cdot \mathrm{s}^{-1}\right.$ fluorescent light $)$ and $80 \%$ relative humidity.

Disease assessment. Disease severity was evaluated on a weekly basis for 10 weeks starting 2 weeks after inoculation. Wilt resistance was assessed on a scale from 0 to 4 based on the percentage of plant tissue affected by chlorosis, leaf, and shoot necrosis or defoliation $(0=$ healthy plant or plant without symptoms; $1=$ plant affected by $1 \%$ to $33 \% ; 2=34 \%$ to $66 \% ; 3=67 \%$ to $99 \% ; 4=$ dead plant). The percentage of dead plants (PDP) and recovery from the disease (LópezEscudero and Blanco-López, 2001, 2005; Tjamos et al., 1991; Wilhelm and Taylor, 1965) were considered to estimate the severity of the reactions. The area under the disease progress curve (Campbell and Madden, 1990) for each cultivar was estimated with reference to the maximum value potentially reached over the 10 -week assessment period (AUDPCP) according to this formula: $\mathrm{AUDPCP}=\left[\left(\mathrm{t} / 2 \times\left(\mathrm{S}_{2}+2 \times \mathrm{S}_{3}+\ldots+\right.\right.\right.$ $\left.\left.2 \mathrm{~S}_{\mathrm{i}-1}+\mathrm{S}_{\mathrm{i}}\right) / 4 \times \mathrm{n}\right] \times 100($ where $\mathrm{t}=$ interval in days between observations; $S_{i}=$ final mean severity; 4 = maximum disease rating; $\mathrm{n}=$ number of observations). Plant infection was confirmed by isolating the fungus from affected shoots or leaf petioles in affected plants during the experiments. Isolations from shoots and branches were made from all dead plants at the end of the experiments. Samples of affected tissue were washed in running tap water, the bark removed, and woody tissue surface disinfected in $0.5 \%$ sodium hypochlorite for $1 \mathrm{~min}$. Wood chips were placed on PDA plates and incubated at $24{ }^{\circ} \mathrm{C}$ in the dark for 5 to $6 \mathrm{~d}$.

Experimental design and data analysis. Plants were arranged according to a completely randomized block design. An analysis of variance of the AUDPCP values reached in the two replications of each experiment and between experiments by the reference cultivars (Picual and Frantoio) was used to determine variability between experiments and replications. Statistical analyses were performed using Statistix 8.0 program (Analytical Software, Tallahassee, Fla.). Mean values were compared by Fisher's protected least significant difference test at $P=0.05$.

Classification of cultivars according to resistance. Olive cultivar resistance to verticillium wilt was categorized according to the criteria of López-Escudero et al. (2004). Thus, cultivars were classified in five resistance categories corresponding to the following AUDPCP ranges: highly resistant $=0 \%$ to $10 \%$; resistant $(\mathrm{R})=11 \%$ to $30 \%$; moderately susceptible (MS) $=31 \%$ to $50 \%$; susceptible (S) $=51 \%$ to $70 \%$; and extremely susceptible (E) $=71 \%$ to $100 \%$. The final values of PDP, the final mean symptom severity (FMS), and the ability of plants to recover from infection, expressed in terms of the symptom remission during the experimental period (López-Escudero and Blanco-López, 2001, 2005; Tjamos et al., 1991; Wilhelm and Taylor, 1965), were also considered for the final classification of cultivars. Plants were considered to be resistant when exhibited FMS values lower than 1.5 and no dead plant; moderately susceptible, FMS between 1.5 and 2.5 and PDP up to $30 \%$; susceptible, FMS higher than 2.5 and PDP between $30 \%$ and $50 \%$; and extremely susceptible, FMS and PDP higher than 3.0 and $50 \%$, respectively.

\section{Results}

Disease symptoms. Chlorosis eventually affected almost all the inoculated plants at a given time during the experiments. It was slight and temporary in plants of 'Frantoio', 'Bodoquera', 'Manzanilla Picúa', and 'Koroneiki'. Nevertheless, in cultivars such as 'Jlot', 'Maelia', and 'Pajarera', chlorosis was extensive and progressive and, with the exception of a very slight defoliation, it was the only disease symptom expressed by these plants.

Defoliation of green leaves developed intensive and abruptly during weeks 4 to 6 after inoculation in several plants of 'Athalassa', 'Cañivano Negro-1', 'Chalchali-1', 'Cordobés de Arroyo de la luz', 'Figueretes', 'Macho de Jaén', 'Mission Moojesky', and 'Mission Nyeland'. Thereafter, these plants showed main stems completely defoliated with only groups of leaves remaining attached to their upper parts. Defoliation of green leaves was however progressive in the rest of the plants, occurring partially in only some of the shoots. Defoliation usually occurred on leaves that previously showed extensive yellowing, particularly in inoculated plants of 'Figueretes', 'Macho de Jaén', and 'Negrillo de Arjona'. In some of the plants, yellowing was restricted to the basal leaves of the main and lateral stems above the inoculation hole in cultivars such as 'Corneja'.

Sudden wilt syndrome or apoplexy was generalized in several susceptible cultivars, affecting the whole plant in 'Athalassa', 'Flasou', or 'Picual'. These plants died progressively over a period of 3 to 5 weeks. Conversely, this syndrome was usually 
partial in plants of other cultivars such as 'Carrasqueño de Porcuna', appearing restricted only to one or two shoots.

Symptoms in the susceptible 'Picual' were variable, starting in some plants at 4 weeks after inoculation with a slight and partial defoliation affecting only some branches of the cuttings but becoming intensive and generalized in others. Later, between the sixth and the seventh week, apoplexy appeared affecting the whole plant or some of the secondary stems that had only slight defoliations. Most 'Frantoio' plants remained free of symptoms during the evaluation period with the exception of very slight defoliations or chlorosis recorded in three of the plants and wilt development and desiccation in a fourth one that reached a maximum value of 2.5 in the symptom severity scale.

Noninoculated control plants did not exhibit any of the symptoms described previously. On the contrary, after 4 or 5 weeks in the growth chamber, these plants produced new buds and twigs normally, revealing the absence or the delay in growth observed in inoculated plants with respect to the control plants was an important disease symptom. Concerning this point, disease recovery, characterized by the detention or decrease of the disease symptom expression, was observed in plants of 'Frantoio', 'Manzanilla Picúa', and 'Grosal de Albocafer' (Figs. 1 and 2), and it was accompanied by the production of new green tissues. Moreover, production of new shoots below the inoculation point in the main stem was observed in some plants highly wilted.

Progress of the disease parameters and classification of resistance. No significant differences between the two corresponding replications in any of the two experiments were found. Moreover, the resistance shown by 'Picual' (susceptible) and 'Frantoio' (resistant), the reference cultivars, showed no differences between the two experiments (Table 2). Thus, final values of the disease parameters allowed the comparison between cultivars evaluated in the two experiments.

Five cultivars, 'Macho de Jaén', 'Chalchali-1', 'Mission Moojeski', 'Cañivano Negro', and 'Cordobés de Arroyo de la Luz', were catalogued as extremely susceptible because these cultivars showed AUDPCP values higher than $70 \%$ or PDP higher than $50 \%$ (Table 1 ). These values were accompanied by severe FMS values, always higher than 3.0 (Table 1; Figs. 1 and 2). The defoliating $V$. dahliae isolate V117 caused AUDPCP ranging from $50 \%$ to $70 \%$ and FMS higher than 3.0 in 'Aloreña-1', 'Athalassa', 'Figueretes', and 'Mission Nyeland'. Three months after the inoculations, these cultivars exhibited a range of mortality from $37.5 \%$ to $50 \%$ and were considered susceptible. 'Picual' and 'Flasou' were catalogued as susceptible despite showing lower AUDPCP values, because they showed severe FMS, close to 3.0. The group classified as moderately susceptible was comprised of cultivars with FMS values lower than 2.6 and AUDPCP ranging
Table 2. Values of final disease parameters of reference cultivars Picual and Frantoio in experiments to test cultivar resistance.

\begin{tabular}{lllll}
\hline & & \multicolumn{3}{c}{ Final disease parameter } \\
\cline { 3 - 5 } Cultivar & Expt. & AUDPCP $^{\mathrm{z}}(\%)$ & FMS $^{\mathrm{y}}$ & PDP $^{\mathrm{x}}(\%)$ \\
\hline Picual & I & $50.9 \mathrm{a}^{\mathrm{w}}$ & $3.2 \mathrm{a}$ & $38.0 \mathrm{a}$ \\
& II & $47.5 \mathrm{a}$ & $2.9 \mathrm{a}$ & $50.0 \mathrm{a}$ \\
& Mean $^{\mathrm{v}}$ & $49.2 \mathrm{x}$ & $3.0 \mathrm{x}$ & $44.0 \mathrm{x}$ \\
Frantoio & I & $6.7 \mathrm{a}$ & $0.3 \mathrm{a}$ & 0.0 \\
& II & $13.8 \mathrm{a}$ & $0.7 \mathrm{a}$ & 0.0 \\
& Mean & $10.2 \mathrm{y}$ & $0.5 \mathrm{y}$ & $0.0 \mathrm{y}$ \\
\hline
\end{tabular}

${ }^{2}$ AUDPCP $=$ area under the disease progress curve with reference to the maximum value potentially reached over the assessment period.

${ }^{\mathrm{y}} \mathrm{FMS}=$ final mean severity of symptoms 12 weeks after inoculation.

${ }^{x} \mathrm{PDP}=$ percentage of dead plants.

${ }^{\text {w}}$ Values are the mean of the two replications of each experiment. For the same cultivar between experiment values in columns followed by the same letter are not statistically significant according to least significant difference test at $P=0.5$.

${ }^{\vee}$ For the same final disease parameter and different cultivars, mean values followed by different letters are statistically significant according to least significant difference test at $P=0.5$.

from $31 \%$ and $50 \%$ such as 'Corneja', 'De Sal', and 'Koroneiki' (Fig. 2). The cultivar 'Bodoquera' was included in this group because it reached FMS values nearly moderate (Table 1; Fig. 1).

Finally, the pathogen did not kill any plants of 'Frantoio', 'Grosal de Albocafer', 'Kato

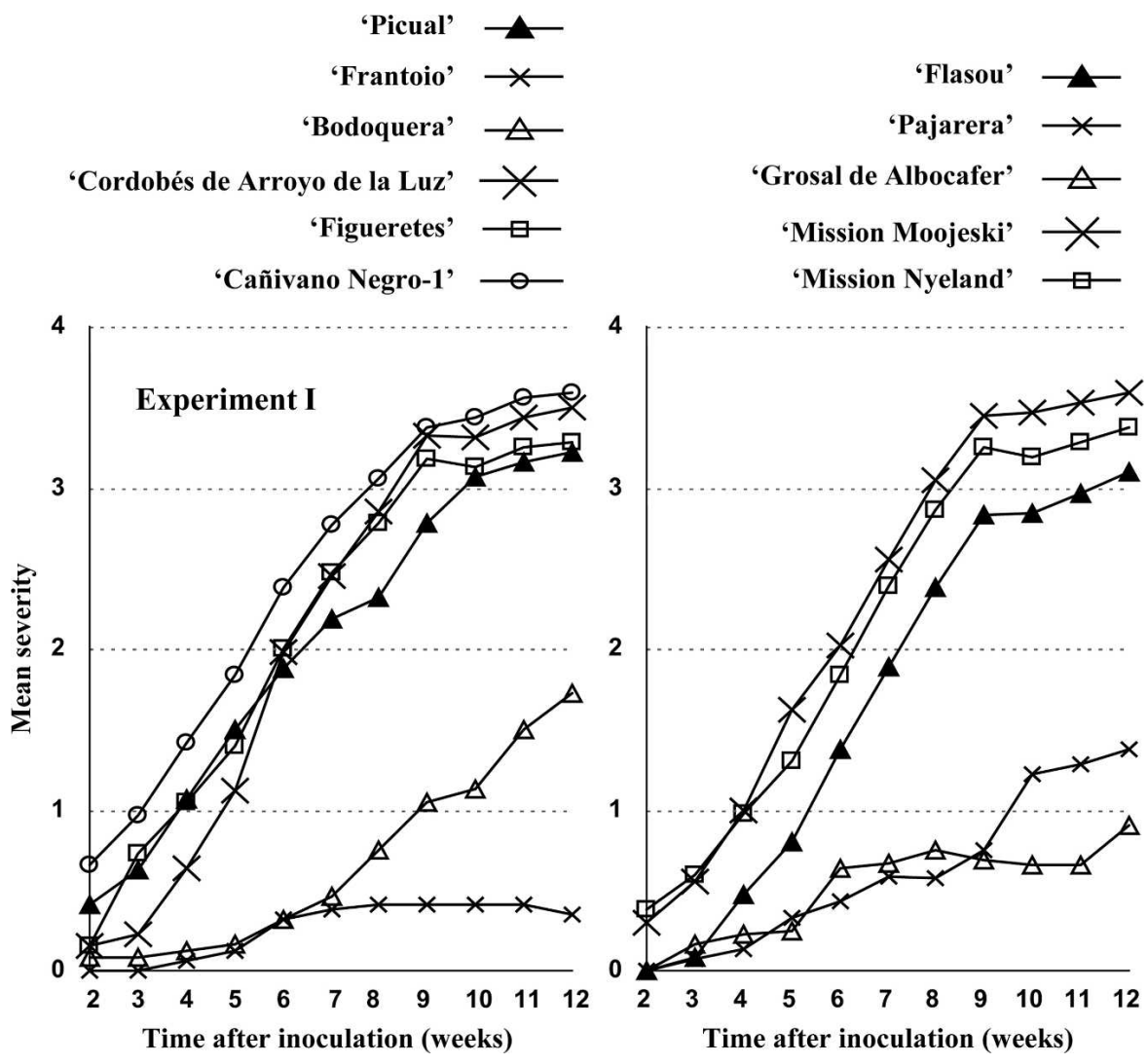

Fig. 1. Disease progress curves based on symptom severity of olive cultivars inoculated by stem puncture with the defoliating isolate V117 of Verticillium dahliae in Expt. I. Assessment of wilt symptom severity was made for 12 weeks beginning 2 weeks after inoculation and based on a scale of 0 to 4 according to percentage of plant tissue affected by necrosis of leaves and twigs, chlorosis, defoliation, or rolling of leaves $(0=$ healthy plant or plant with no symptoms; $1=1 \%$ to $33 \% ; 2=34 \%$ to $66 \% ; 3=$ $67 \%$ to $99 \%$ and $4=$ dead plant). Values are the mean of two replications of the experiment. 


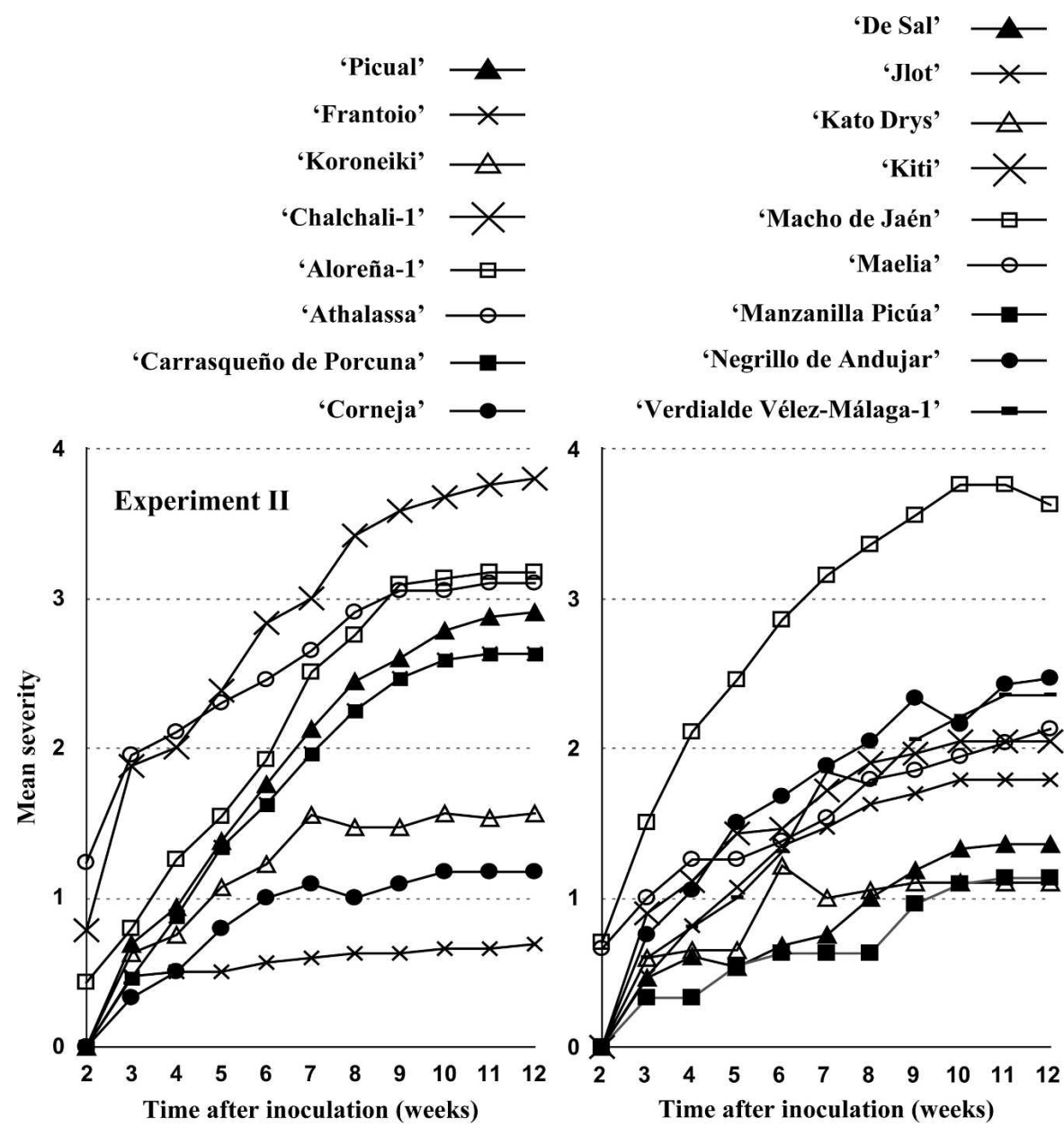

Fig. 2. Disease progress curves based on symptom severity of olive cultivars inoculated by stem puncture with the defoliating isolate V117 of Verticillium dahliae in Expt. II. Assessment of wilt symptom severity was made for 12 weeks beginning 2 weeks after inoculation and based on a scale of 0 to 4 according to percentage of plant tissue affected by necrosis of leaves and twigs, chlorosis, defoliation, or rolling of leaves $(0=$ healthy plant or plant with no symptoms; $1=1 \%$ to $33 \% ; 2=34 \%$ to $66 \% ; 3=$ $67 \%$ to $99 \%$ and $4=$ dead plant).Values are the mean of two replications of the experiment.

magnitude and extension of some of the described symptoms were different. Thus, chlorosis had been more frequently observed in trees inoculated with nondefoliating isolates of the pathogen in the mentioned works. Moreover, this symptom seemed to be associated to infections by the defoliating one mainly in cultivars showing certain levels of resistance (López-Escudero et al., 2004). Nevertheless, in the present study, chlorosis was the most common symptom observed in the plants. Moreover, the incidence of trees showing extensive or complete dieback affecting the whole plant was higher in the root dip-inoculated plants of the cited works than in plants inoculated in this work by stem injection. Additionally, this symptom appeared later in this work. Defoliation of still green leaves or after yellowing also developed more slowly over time in some of the cultivars in this study regarding the progress after inoculations through the roots.

The effect of the reduction or the delay of the symptoms were manifested in the AUDPCP and FMS values for the reference cultivars 'Picual' $(49.2 \%$ and 3.0 , respectively) and 'Frantoio' ( $10.2 \%$ and 0.5 , respectively), recorded in this work, that were lower than those observed in the previous cited works $(60.2 \%$ and 3.7 for 'Picual' and $19.8 \%$ and 0.9 for 'Frantoio'). Furthermore, wider differences were reached in the PDP values when the two methods were compared, particularly in the susceptible cultivar. Thus, mortality in 'Picual' incited by root dip inoculation with a defoliating isolate accounted for $81.2 \%$ of the trees in the studies of López-Escudero et al. (2004), Martos-Moreno et al. (2006), and RayaOrtega (2005) and the $44 \%$ in this study.

Differences among the colonization rates induced by a defoliating isolate of $V$. dahliae in olive between 'Picual' (susceptible) and 'Oblonga' (resistant), which seems to be the same cultivar as 'Frantoio' (Barranco et al., 2000), were well documented by RodríguezJurado et al. (1993) using root dip inoculation. Our results suggest these differences between susceptible and resistant cultivars could be more pronounced when the stem puncture inoculation is used. Probably, it could be explained because stem puncture does not provide the natural way for the pathogen to penetrate the plant and, subsequently, pathogen colonization does not reach an appropriate level to induce high disease severity as reached by root dip inoculation. In this respect, in studies aimed at selecting resistant cultivars to $V$. dahliae in cocoa using stem puncture, Resende et al. (1995) observed that the resistance of some cocoa cultivars still remained effective when the inoculum density was increased from $10^{4}$ up to $10^{8}$ conidia $\cdot \mathrm{mL}$. It suggests that another inoculation method should be necessary to overcome plant resistance and not only to increase the pathogen amount directly introduced into the xylem in the aerial part of the plant.

On the other hand, the production of new shoots below the inoculation point in the main stem has been observed in some plants after a severe and extensive wilt symptom development. This fact indicates that, when the stem puncture inoculation is used, the pathogen is not able to kill all the plants in which it has induced severe disease symptoms. On the contrary, root dip inoculation in olive, using the same plant material and the same defoliating $V$. dahliae strain (V117), did not allow plants to recover from infections when symptoms were very severe (López-Escudero and Blanco-López, 2005).

Susceptibility is a consequence of the inadequate reaction of the plant to impede the transversal and longitudinal colonization of new vessels by the pathogen as a result of the production of gel plugs, tyloses, and gums that can finally induce severe vessel plugging (Beckman, 1989; Rodríguez-Jurado, 1993). These reactions could be promoted more intensively by the pathogen during the penetration and colonization activities in the roots, although these can be also activated by artificial inoculations in the aerial part of the plant, as reported by Zentmeyer et al. (1955) in avocado or by Resende et al. (1995) in cocoa. This could finally suggest that the differences of symptom severity incited by stem puncture or root dip inoculation can be explained by differences in the distribution of the pathogen within the plant as a result of fungus moving mainly upward, starting the infection in the stem area in the first case. A last point to be considered is the higher percentage of plants escaping from infections using this methodology with regard to the infection effectiveness provided by the root dip inoculation (Blanco-López et al., 1998).

In this study, ranges of AUDPCP used for establishing resistance categories have been the same than those used by López-Escudero et al. (2004) and Martos-Moreno et al. (2006) using root dip inoculation. Consequently, an important number of assessed cultivars fell in the resistant or moderately susceptible categories, because symptom severity was generally slighter by this inoculation method. However, high values of FMS and PDP have been considered for modifying the classification and, therefore, some cultivars have been displaced to the lower category of resistance. This is the case for 'Bodoquera', 'Flasou', and 'Picual', which showed higher FMS values than the FMS mean value of the group in which these should have been catalogued if only the AUDPCP ranges had been 
considered. Besides 'Picual' and 'Frantoio', for which the susceptibility level to this defoliating isolate of $V$. dahliae had been previously reported, the Greek cultivar 'Koroneiki' had also been previously tested by Martos-Moreno et al. (2006) and RayaOrtega (2005) by root dip inoculation, showing in the present study similar values of AUDPCP and FMS but half of dead plants using the stem puncture method.

Stem puncture can be considered appropriate to differentiate resistant and susceptible olive cultivars. Thus, 11 of the total cultivars evaluated in this study have been catalogued as susceptible or extremely susceptible and, although this is the only available information about their resistance to $V$. dahliae, it is expected that the reactions of these cultivars should be more severe if inoculation by roots were used. In some cases, extra information obtained from observations made during field surveys in olive orchards (Al-Ahmad and Mosli, 1993; Wilhelm and Taylor, 1965) shows differences in resistance in some cultivars in relation to that expressed in our studies. It might be thought contradictory; however, the incomplete or incorrect identification of the cultivar can be the reason for result variability. Moreover, some surveys could have been carried out in zones where only low inoculum densities of nondefoliating $V$. dahliae isolates are present in soil. Thus, Wilhelm and Taylor (1965) have reported that 'Mission' is very susceptible in California, like 'Mission Moojeski' and 'Mission Nyeland' in our study, but it is likely that no one of these two genotypes corresponds to 'Mission'. Similarly, the different degree of susceptibility between our Syrian 'Chalchali-1', extremely susceptible, and the 'Chalchali' reported by Al-Ahmad and Mosli (1993), considered with a certain level of resistance, can be explained because our 'Chalchali-1' tree has been confirmed as an erroneous denomination, that being the reason for adding the 1 to its name. Thus, for avoiding possible misunderstandings when classifying olive cultivars by their resistance to Verticillium wilt, it is necessary to consider the identification level of the varietal denominations studied as well as the evaluation procedure used in each case. Finally, cultivars moderately susceptible or resistant, with AUDPCP lower than 30\% and, particularly, these ones that have not showed dead plants, should be tested again by root dip inoculation for confirming their resistance level, thus allowing to recommend them to be used in breeding or rootstock selection programs.

\section{Literature Cited}

Al-Ahmad, M.A. and M.N. Mosli. 1993. Verticillium wilt of olive in Syria. EPPO Bul. 23:521529.

Barranco, D., I. Trujillo, and P. Rallo. 2000. Are 'Oblonga' and 'Frantoio' olives the same cultivar? HortScience 35:1323-1325.

Beckman, C.H. 1989. Colonization of the vascular system of plants by fungal wilt pathogens: A basis for modelling the interactions between host and parasite in time and space, p. 19-32. In: E.C. Tjamos and C.H. Beckman (eds.). Vascular wilt diseases of plants, Vol. 28. Springer-Verlag, N.Y. NATO ASI Series H, Cell Biology.

Blanco-López, M.A., J. Bejarano-Alcázar, J.M. Melero-Vara, and R.M. Jiménez-Díaz. 1989. Current status of Verticillium wilt of cotton in southern Spain. Pathogen variation and population in soil, p. 123-133. In: E.C. Tjamos and C.H. Beckman (eds.). Vascular wilt diseases of plants. Vol. 28. Springer-Verlag, N.Y. NATO ASI Series H: Cell Biology.

Blanco-López, M.A., J. Hiemstra, D. Harris, F.J. López-Escudero, and P. Antoniou. 1998. Selection and screening for host resistance, p. 51-54. In: J. Hiemstra and D. Harris (eds.). Compendium of Verticillium wilt in tree species. Ponsen \& Looijen, Wageningen, The Netherlands.

Blanco-López, M.A., R.M. Jiménez-Díaz, and J.M. Caballero. 1984. Symptomatology, incidence and distribution of Verticillium wilt of olive trees in Andalucía. Phytopathol. Mediterr. 23:1-8.

Caballero, J.M. and C. Del Río. 2005. Bancos de Germoplasma (Banco de Germoplasma Mundial de Córdoba), p. 235-246. In: L. Rallo, D. Barranco, J.M. Caballero, C. Del Río, L. Martín, J. Tous, and I. Trujillo (eds.). Variedades de olivo en España (Libro II: Variabilidad y selección). Junta de Andalucía, MAPA y Ediciones Mundi-Prensa, Madrid, Spain.

Caballero, J.M., C. Del Río, D. Barranco, and I. Trujillo. 2006. The Olive World Germoplasm Bank of Córdoba, Spain. Olea 25:14-19.

Campbell, C.L. and L.V. Madden. 1990. Introduction to plant disease epidemiology. John Wiley \& Sons, N.Y.

Cirulli, M. and G. Montemurro. 1976. A comparison of pathogenic isolates of Verticillium dahliae and sources of resistance in olive. Agriculturae Conspectus Scientificus 39:469476.

Civantos, L. 2004. La olivicultura en el mundo y en España, p. 17-35. In: D. Barranco, R. Fernández-Escobar, and L. Rallo (eds.). El cultivo del olivo. Junta de Andalucía y Ediciones MundiPrensa, Madrid, Spain.

Hartman, H., W.C. Schnathorst, and J. Whysler. 1971. Oblonga, a clonal olive rootstock resistant to Verticillium wilt. Calif. Agr. 25:13-15.

Hiemstra, J. and D. Harris. 1998. Compendium of Verticillium wilt in tree species. Ponsen \& Looijen, Wageningen, The Netherlands.
López-Escudero, F.J. and M.A. Blanco-López. 2001. Effect of a single or double soil solarization to control Verticillium wilt in established olive orchards in Spain. Plant Dis. 85:489-496.

López-Escudero, F.J. and M.A. Blanco-López. 2005. Recovery of young olive trees from Verticillium dahliae. Eur. J. Plant Pathol. 113:367-375.

López-Escudero, F.J., C. del Río, J.M. Caballero, and M.A. Blanco-López. 2004. Evaluation of olive cultivars for resistance to Verticillium dahliae. Eur. J. Plant Pathol. 110:79-85.

Markakis, E.A., P.P. Antoniou, S.E. Tjamos, E.J. Paplomatas, and E.C. Tjamos. 2006. Study of the resistance of the olive tree cultivars Amfissis and Kalamon to Verticillium dahliae, p. 185-186. Proc. 12th Congress of the Mediterranean Phytopathological Union, Rhodes Island, Hellas.

Martos-Moreno, C., F.J. López-Escudero, and M.A. Blanco-López. 2006. Resistance of olive cultivars to the defoliating pathotype of Verticillium dahliae. HortScience 41:1313-1316.

Paplomatas, E.J. and K. Elena. 2001. Reaction of Greek olive cultivars to the cotton defoliating strain of Verticillium dahliae. 8th International Verticillium Symposium, 5-8 Nov. 2001 Córdoba, Spain. P: 51 (Abstract).

Pennisi, A.M., S.O. Cacciola, G. Magnano di San Lio, and G. Perrotta. 1993. Evaluation of the susceptibility of olive cultivars to Verticillium wilt. EPPO Bul. 23:537-541.

Raya-Ortega, M.C. 2005. Resistencia en olivo a Phytophthora spp y Verticillium dahliae, University of Córdoba, Spain, $\mathrm{PhD}$ Thesis.

Resende, M.V.L., J. Flood, and R.M. Cooper. 1995. Effect of methods of inoculation, inoculum density and seedling age at inoculation on the expression of resistance of cocoa (Theobroma cacao L.) to Verticillium dahliae Kleb. Plant Pathol. 43:104-111.

Rodríguez-Jurado, D. 1993. Interacciones huesped-parasito en la marchitez del olivo (Olea europaea L.) inducida por Verticillium dahliae Klebs. University of Córdoba, Spain, $\mathrm{PhD}$ Thesis.

Rodríguez-Jurado, D., M.A. Blanco-López, H.F. Rapoport, and R.M. Jiménez-Díaz. 1993. Present status of Verticillium wilt of olive in Andalucía (southern of Spain). EPPO Bul. 23:513-516.

Serrhini, M.N. and A. Zeroual. 1995. La Verticilosis del olivo en Marruecos. Olivae 58:58-61.

Tjamos, E.C., D.A. Biris, and E.J. Paplomatas. 1991. Recovery of olive trees with Verticillium wilt after individual application of soil solarization in established olive orchards. Plant Dis. 75:557-562.

Wilhelm, S. and J.B. Taylor. 1965. Control of Verticillium wilt in olive through natural recovery and resistance. Phytopathology 55:310-316.

Zentmeyer, G.A., F.F. Halma, and S. Wilhelm. 1955. Relative susceptibility of Guatemalan and Mexican avocado rootstocks to Verticillium wilt. Phytopathology $8: 80-81$. 